\title{
Anthropometric Study of the Bicipital Groove in Indians and Its Clinical Implications
}

\author{
B. V. Murlimanju, MD; Latha V. Prabhu, MS; Mangala M. Pai, MD; M. Shreya, MSc; \\ K. U. Prashanth, MBBS; Chettiar Ganesh Kumar, MD; Chitra Prakash Rao, MS
}

Background: Since morphometric data on the upper end of the humerus from Indian anatomical samples are scarce, this study was undertaken with reference to orthopedic surgery. The aim was to determine the length, width and depth of the bicipital groove and to find the incidence of a supratubercular ridge of Meyer in an Indian population.

Methods: The study included 104 unpaired dry humeri (48 right side and 56 left) which belonged to the anatomy laboratory of our institution. The length, width and depth of the bicipital groove were measured with a digital vernier caliper. The data were tabulated as mean $\pm \mathrm{SD}$ and statistically compared between the right and left sides.

Results: $\quad$ The mean length, width and depth of the bicipital groove were $84.6 \pm 10.9$ $\mathrm{mm}, 8.5 \pm 2.3 \mathrm{~mm}$ and $4.4 \pm 1.8 \mathrm{~mm}$, respectively, which corresponded to $27.8 \%$ of the total length, $32.2 \%$ of the transverse width and $17 \%$ of the anteroposterior widh of the humerus, respectively. There was no statistically significant difference in these parameters between the left and right sides $(p$ $>0.05)$. A supratubercular ridge of Meyer was seen in $24(23.1 \%)$ of the humeri.

Conclusion: The study determined the morphometric parameters of the bicipital groove in an Indian population. We believe that this study will be an important reference for scientific research, and the details are also important for anthropologists and clinical anatomists.

(Chang Gung Med J 2012;35:155-9)

Key words: anthropometry, bicipital groove, dry bone, intertubercular sulcus, morphometry, supratubercular ridge

\begin{abstract}
$\Lambda^{n}$ n understanding of normal humeral morphology is important, since recreation of normal anatomy is the goal in prosthetic replacement of the upper end of the humerus. This knowledge can affect prosthetic sizing, positioning and design. ${ }^{(1)}$ The bicipital groove (BG) offers a useful landmark for placement
\end{abstract}

of the lateral fin of a prosthesis in shoulder arthroplasty. It was also reported that the BG can be used as a landmark for humeral head replacement in fractures of the upper end of the humerus. ${ }^{(2)}$

The intertubercular sulcus is between the greater and lesser tubercles and it continues distally for

From the Department of Anatomy, Centre for Basic Sciences, Kasturba Medical College, Manipal University, Bejai, Mangalore, India.

Received: Jan. 31, 2011; Accepted: Oct. 17, 2011

Correspondence to: Dr. B. V. Murlimanju, Department of Anatomy, Centre for Basic Sciences, Kasturba Medical College, Manipal University, Bejai, Mangalore, India. Centre for Basic Sciences, Kasturba Medical College, Bejai, Mangalore-575004, India.

Tel: 91-824 2211746; Fax: 91-824 2421283; E-Mail: flutesnowmm@gmail.com 
about $5 \mathrm{~cm}$ on the shaft of the humerus, which altogether is called the BG. ${ }^{(3)}$ It contains the long head of the biceps brachii muscle, its synovial sheath and an ascending branch of the anterior circumflex humeral artery. Its lateral lip is marked by the bilaminar tendon of the pectoralis major, its floor by the tendon of the latissimus dorsi and its medial lip by the tendon of the teres major. The transverse humeral ligament is a broad band which passes between its tubercles and converts the sulcus into a canal and acts as a retinaculum for the long tendon of the biceps. ${ }^{(4)}$

Anatomical knowledge of the BG is important as abnormalities of the bicipital tendon and its synovial sheath have been implicated in a variety of causes of shoulder pain and disability. ${ }^{(5,6)}$ A radiological study recommended that the entire length of the BG be examined to determine the osseous anatomy of the groove. ${ }^{(7)}$ Few authors have studied the morphology of the upper end of the humerus, ${ }^{(1,8-10)}$ and data related to the BG are scanty in the literature. The aim of the present study was to determine the length, width and depth of the BG in an Indian population. The incidence of the supratubercular ridge of Meyer was also determined.

\section{METHODS}

The study included 104 unpaired dry humeri (48 right side and 56 left) which belonged to the anatomy laboratory of our institution. The age and sex of the donors of the specimens were not determined and the humeri did not have any external deformities. The upper end of all bones was studied (Figure). The length, width and depth of the BG were measured with a digital vernier caliper. The lengths of the humeri were measured using an osteometric board. The anteroposterior and transverse widths of the humerus were measured at the surgical neck with a digital vernier caliper. The maximum width of the BG recorded at any point was considered its width. The depth was measured at the midpoint of the tubercles. The data were recorded separately for right and left humeri. Statistical analysis between the sides was performed using the independent t-test. Two tailed $p$-values $<0.05(\alpha=0.05)$ were considered significant. The SPSS 15.0 program was used for statistical analysis (SPSS Inc., Chicago, Illinois, U.S.A.). Data were presented as mean \pm SD. The humeri were also observed for the presence of a

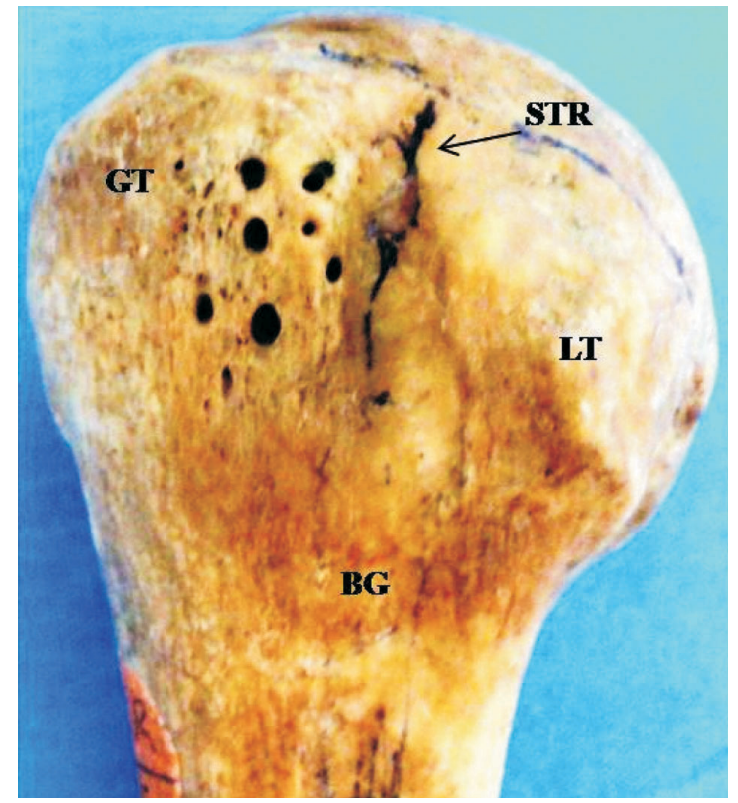

Figure Upper end of the humerus. Abbreviations used: GT: greater tubercle; LT: lesser tubercle; BG: bicipital groove; STR: supratubercular ridge of Meyer (seen in $23.1 \%$ of cases in the present study).

supratubercular ridge of Meyer. The supratubercular ridge was defined as a bony ridge extending proximally from the lesser tubercle more than half the distance to the humeral head. ${ }^{(11)}$

\section{RESULTS}

The mean length, width and depth of the BG were $84.6 \pm 10.9 \mathrm{~mm}, 8.5 \pm 2.3 \mathrm{~mm}$ and $4.4 \pm 1.8$ $\mathrm{mm}$, respectively. These measurements corresponded to $27.8 \%$ of the total length, $32.2 \%$ of the transverse width and $17 \%$ of the anteroposterior width of the humerus, respectively. The mean length of the humerus from its upper to lower ends, transverse width at the surgical neck and anteroposterior width at the surgical neck were $304 \pm 23 \mathrm{~mm}, 26.4 \pm 4.1$ and $25.9 \pm 4.3 \mathrm{~mm}$, respectively. Data were analyzed between the sides and the detailed values are presented in Table 1. The mean length of the humerus was longer on the right side than the left ( $p$ $=0.00$ ). Other than this, no parameters showed statistically significant differences $(p>0.05)$ between the right and left sides. A supratubercular ridge of Meyer (Figure) was identified in $24(23.1 \%)$ of the 
Table 1. Comparison of Measurements of Right and Left Humeri $(\mathrm{n}=104)$

\begin{tabular}{lccc}
\hline Parameter $(\mathrm{mm})$ & right side & left side & $p$ value \\
\hline length of the bicipital groove & $86 \pm 10.1$ & $83.3 \pm 11.5$ & 0.53 \\
width of the bicipital groove & $8.3 \pm 2.4$ & $8.7 \pm 2.2$ & 0.48 \\
depth of the bicipital groove & $4.7 \pm 2$ & $4.2 \pm 1.6$ & 0.05 \\
length of the humerus* & $309.8 \pm 18.1$ & $299.9 \pm 25.4$ & 0.00 \\
transverse width of humerus & $27.4 \pm 4.3$ & $25.5 \pm 3.8$ & 0.37 \\
anteroposterior width of humerus & $27.5 \pm 4.3$ & $24.6 \pm 3.9$ & 0.76 \\
\hline
\end{tabular}

Values are mean $\pm \mathrm{SD}$, Statistical significance (independent $t$-test). $*: p$ $<0.05$.

humeri. Of those, $16(15.4 \%)$ were present on the right humerus.

\section{DISCUSSION}

The tendon of the long head of the biceps plays an important role in maintaining the alignment of the head of the humerus within the glenoid cavity of the scapula. The humerus moves on the tendon of the long head of the biceps in all movements of the upper limb. ${ }^{(12)}$ Many authors feel that a shallow intertubercular groove combined with an supratubercular ridge of Meyer predisposes a patient to bicipital disease. ${ }^{(13-15)}$ Subluxation and dislocations of the biceps tendon are more common in people with a shallow intertubercular sulcus. ${ }^{(6,16,17)}$ During rotation of the shoulder, a shallow BG can cause trauma to the biceps tendon because of impingement of structures like the acromion, rotator cuff and coracoacromial arch. ${ }^{(14)}$ The morphology of the BG has significant variability and affects the biomechanics of the tendon, and certain morphologic characteristics have been implicated in the development of bicipital tendinitis. ${ }^{(18)}$

Although the BG is a subject of clinical interest, anatomical studies are scarce. Anatomic variations in the groove could give rise to sliding of the biceps brachii muscle tendon. ${ }^{(19)}$ In Wafae et al.'s morphometric study, ${ }^{(19)}$ the average length of the groove corresponded to $25.2 \%$ of the length of the humerus. The width at the midpoint of the groove corresponded to $49.7 \%$ to $54.5 \%$ of the width of humerus. The depth corresponded to $18.8 \%$ of the depth of humerus. In the present study, the mean length of the BG corresponded to $27.8 \%$ of the total length of humerus, the mean width to $32.2 \%$ of the total humeral width, and the mean depth to $17 \%$ of the total anteroposterior width of the humerus. We observed that our data were similar to that of Wafae et al. ${ }^{(19)}$ However, statistical comparison with the Wafae et al study was not possible because that study did not provide standard deviations for their data. ${ }^{(19)}$ The data from these two studies are shown in Table 2. ${ }^{(19)}$

It has been reported that $90-95 \%$ of people are right-handed. ${ }^{(20)}$ In the manual workers, the pressure of the tendon of the long head of the biceps is higher on the right side than on the left, which may be expected to change the morphometry of the BG. ${ }^{(21)}$ Vettivel et al. observed that the mean width of the BG was greater on the right than the left humeri and the mean depths of the BG on right and left sides were similar. ${ }^{(21)}$ The biceps is a muscle for heavy work and it is hypertrophied in manual laborers, ${ }^{(22)}$ with a resultant increase in the size of its long tendon. ${ }^{(21)}$ So the right tendon is larger than the left in the right- handed people and vice versa. But the present study showed no significant differences between the right and left humeri $(p>0.05)$. According to Vettivel et al., ${ }^{(21)}$ the mean length of the right humeri was $30.2 \pm 0.2 \mathrm{~cm}$ and the left was $30.1 \pm 0.2 \mathrm{cms}$. In the present study, these lengths were $31 \pm 1.8$ and $30 \pm 2.5 \mathrm{~cm}$, respectively. The only statistically significant difference in this study was that the right humerus was longer than the left $(p=0.00)$.

It was reported that more pressure on the BG and accommodation of a larger, flat tendon could increase its length, width and depth. Cone et al. did not believe that direct measurements of the width of the groove are of great value in evaluating the BG. ${ }^{(11)}$

Table 2. Comparison of Measurements of Humeri in This Study and the Wafae et al. Study

\begin{tabular}{lcc}
\hline Parameter measured & $\begin{array}{c}\text { Wafae et al. } \\
\text { study (2010) }\end{array}$ & $\begin{array}{c}\text { Present } \\
\text { study (2010) }\end{array}$ \\
\hline Average length of the BG & $81 \mathrm{~mm}$ & $84.6 \pm 10.9 \mathrm{~mm}$ \\
Width of the BG at its midpoint & $10.1 \mathrm{~mm}$ & $8.5 \pm 2.3 \mathrm{~mm}$ \\
Depth of the BG at its midpoint & $4 \mathrm{~mm}$ & $4.4 \pm 1.8 \mathrm{~mm}$ \\
\hline
\end{tabular}

Abbreviation: BG: bicipital groove. 
They reported that wide grooves (i.e., $>17 \mathrm{~mm}$ ) are often shallow, a combination which may predispose to tendon subluxation or dislocation. On patient radiographs, Cone et al. found that the mean depth of the intertubercular sulcus was $4.6 \mathrm{~mm} .{ }^{(11)}$ They also reported that $90 \%$ of their patients had a sulcus with a depth greater than $3 \mathrm{~mm}$ and $86 \%$ had a depth in the range of 4-6 mm. Finally they felt that a groove 3 $\mathrm{mm}$ deep or less should be viewed with suspicion in managing pathologic conditions of the shoulder.

In a study by Pfahler et al., the width and depth of the BG showed sex-related differences. ${ }^{(23)}$ Robertson et al. found that the humeri of men were significantly longer $(35 \pm 2 \mathrm{cms})$ than those of women $(31 \pm 2 \mathrm{cms}){ }^{(1)}$ In the present study we didn't determine the sex of the donors of the humeri. The supratubercular ridge, described by Meyer in $1928^{(24)}$ and later by Hitchcock and Bechtol, ${ }^{(16)}$ consists of a bony projection that is continuous with the superior aspect of the lesser tubercle. It was reported that this ridge changes the direction of the biceps tendon as it enters the groove by elevating and forcing it laterally. ${ }^{(11)}$ Hitchcock and Bechtol associated the presence of a supratubercular ridge with bicipital tendinitis. ${ }^{(16)}$ However, Cone et al., from their radiological interpretation, observed the supratubercular ridge as an osseous protuberance in about $50 \%$ of cases and reported that it does not seem to be pathologically significant. ${ }^{(11)}$ Vettivel et al. observed a supratubercular ridge of Meyer in $88 \%$ of right and $57 \%$ of left humeri, and reported that this ridge is probably more necessary on the right side to prevent medial displacement of the long head of the biceps tendon from the BG. ${ }^{(21)}$ In the present study, this ridge was identified in $23.1 \%$ of humeri. Of these, $15.4 \%$ were on the right and $7.7 \%$ were on the left side. This is a low incidence rate compared with previous studies and may be because of racial variations.

The present study was limited in that it did not include parameters such as the height, body build and gender of the donors. The length of the bicipital groove may be related to the height and build of the individual. A person with a broad body build is likely to have larger parameters. The age and occupation may also be especially important for defining the depth and width because increasing age and occupations requiring repetitive and strong movement of the tendon in the groove may influence these parameters.

\section{Conclusion}

We report the morphometric parameters of the bicipital groove in an Indian population. These data are important for the orthopedic literature. Since data from Indian subjects are scarce, this study was undertaken to provide a reference for orthopedic surgeons. The data will be an important reference for scientific research and for anthropologists and clinical anatomists. We believe that the anatomic information obtained herein will provide a baseline for further radiological investigation of the bicipital region.

\section{Acknowledgements}

We gratefully acknowledge all the nonteaching staff members of our department for their help and cooperation.

\section{REFERENCES}

1. Robertson DD, Yuan J, Bigliani LU, Flatow EL, Yamaguchi K. Three-dimensional analysis of the proximal part of the humerus. J Bone Joint Surg Am 2000;82: 1594-602.

2. Itamura J, Dietrick T, Roidis N, Shean C, Chen F, Tibone J. Analysis of the bicipital groove as a landmark for humeral head replacement. J Shoulder Elbow Surg 2002;11:322-6.

3. Joseph J. Locomotor system. In: Hamilton WJ, ed. Textbook of Human Anatomy. London: Macmillan, 1976:19-200.

4. Gray's Anatomy. In: Standring S, ed. The Anatomical Basis of Clinical Practice. 39th ed., Spain: Churchill Livingstone, 2006:823-32.

5. Booth RE, Marvel JP. Differential diagnosis of shoulder pain. Orthop Clin North Am 1975;6:353-79.

6. Slatis P, Aalto K. Medial dislocation of the tendon of the head of the biceps brachii. Acta Orthop Scand 1979;50: 73-7.

7. Farin PU, Jaroma H. The bicipital groove of the humerus: sonographic and radiographic correlation. Skeletal Radiol 1996;25:215-9.

8. Ballmer FT, Sidles JA, Lippitt SB, Matsen FA III. Humeral prosthetic arthroplasty: surgically relevant considerations. J Shoulder Elbow Surg 1993;2:296-304.

9. Iannotti JP, Gabriel JP, Schneck SL, Evans BG, Misra S. The normal glenohumeral relationships. An anatomical study of one hundred and forty shoulders. J Bone Joint Surg Am 1992;74:491-500.

10. Roberts SN, Foley AP, Swallow HM, Wallace WA, Coughlan DP. The geometry of the humeral head and the design of prostheses. J Bone Joint Surg Br 1991;73:64750 . 
11. Cone RO, Danzig L, Resnick D, Goldman AB. The bicipital groove: radiographic, anatomic and pathologic study. AJR Am J Roentgenol 1983;141:781-8.

12. Travill A, Basmajian JV. Electromyography of the supinators of the forearm. Anat Rec 1961;139:557-60.

13. Martinoli C, Bianchi S, Prato N, Pugliese F, Zamorani MP, Valle M, Derchi LE. US of the shoulder: non-rotator cuff disorders. Radiographics 2003;23:381-401.

14. DePalma AF. Surgical anatomy of the rotator cuff and the natural history of degenerative periarthritis. Clin Orthop Relat Res 2008;466:543-51.

15. Abboud JA, Bartolozzi AR, Widmer BJ, DeMola PM. Bicipital groove morphology on MRI has no correlation to intra-articular biceps tendon pathology. J Shoulder Elbow Surg 2010;19:790-4.

16. Hitchcock HH, Bechtol CO. Painful shoulder. J Bone Joint Surg Am 1948;30:262-73.

17. Nevaiser RJ. Lesions of the biceps and tendinitis of the shoulder. Orthop Clin North Am 1980;11:343-8.

18. Karistinos A, Paulos LE. Anatomy and function of the tendon of the long head of the biceps muscle. Oper Tech Sports Med 2007;15:2-6.

19. Wafae N, Atencio Santamarıa LE, Vitor L, Pereira LA, Ruiz CR, Wafae GC. Morphometry of the human bicipital groove (sulcus intertubercularis). J Shoulder Elbow Surg 2010;19:65-8.

20. Adams RD, Victor M. Principles of Neurology. 4th ed. Singapore: McGraw Hill, 1989:377-95.

21. Vettivel S, Indrasingh I, Chandi G, Chandi SM. Variations in the intertubercular sulcus of the humerus related to handedness. J Anat 1992;180:321-6.

22. Rasch PJ, Burke RK. Kinesiology and Applied Anatomy. 5th ed. Philadelphia: Lea \& Febiger, 1974:22-40.

23. Pfahler M, Branner S, Refior HJ. The role of the bicipital groove in tendinopathy of the long biceps tendon. J Shoulder Elbow Surg 1999;8:419-24.

24. Meyer AW. Spontaneous dislocation and destruction of tendon of long head of biceps brachii. Fifty-nine instances. Arch Surg 1928;17:493-506. 